\title{
SISTEMAS CARREADORES LIPÍDICOS NANOESTRUTURADOS PARA IVERMECTINA E METOPRENO VISANDO CONTROLE DE PARASITAS
}

\author{
Diego Faria Cola ${ }^{\mathrm{a}}$, Tatiane Pasquoto ${ }^{\mathrm{b}}$, Mariana Guilger ${ }^{\mathrm{b}}$, Renata de Lima ${ }^{\mathrm{b}}$, Camila Morais Gonçalves da Silva ${ }^{\mathrm{c}}$ e Leonardo \\ Fernandes Fraceto ${ }^{\mathrm{a}, \mathrm{c}, *}$ \\ aDepartamento de Engenharia Ambiental, Universidade Estadual Paulista Julio de Mesquita Filho, Av. Três de março, 511, Alto \\ da Boa Vista, 18087-180 Sorocaba - SP, Brasil \\ ${ }^{b}$ Departamento de Biotecnologia, Universidade de Sorocaba, 18023-000 Sorocaba - SP, Brasil \\ 'Departamento de Bioquímica, Instituto de Biologia, Universidade Estadual de Campinas, Cidade Universitária Zeferino Vaz, \\ 13087-970 Campinas - SP, Brasil
}

Recebido em 19/01/2016; aceito em 11/05/2016; publicado na web em 15/07/2016

\begin{abstract}
LIPID NANOSTRUCTURED CARRIERS SYSTEMS FOR IVERMECTIN AND METHOPRENE AIMING PARASITE CONTROL. The study of characteristics of nanoscale structures and applications now has great interest of researchers from different areas. In this regard, lipid carriers can improve the bioavailability of drugs and the reduction of possible toxicological effects. Thus, the development of nanostructured systems for the agricultural sector, aimed at combating parasites may reduce extensive damage caused to livestock producers and animal health. This study aimed to prepare and characterize lipid carrier systems, such as Solid Lipid Nanoparticles (SLN) and Nanostructured Lipid Carriers (NLC), as well as evaluate the potential of cyto and genotoxicity of these systems in order to improve and produce alternatives to the use targeting these compounds in veterinary applications. Lipid nanoparticles had become spherical with an average size of $250 \mathrm{~nm}$ and remained stable over 120 days. The encapsulation efficiency was greater than $99 \%$ for both drugs and release tests showed a strong interaction between drugs and nanoparticles. Cyto- and genotoxicity tests show that nanoparticles made possible changes in cellular viability of the tested cells. Thus, the results showed that the nanoparticles had good colloidal characteristics without changes in its characteristics, enabling the development of carrier systems for these drugs, aiming veterinary applications.
\end{abstract}

Keywords: lipid nanocarriers; parasites; veterinary; genotoxicity; cytotoxicity.

\section{INTRODUÇÃO}

O estudo de características e aplicações de estruturas em escala nanométrica tem apresentado um grande interesse a pesquisadores das áreas médica (humana e animal), ambiental e agrícola. Estas estruturas nanométricas, preparadas de diferentes formas, permitiram o avanço da nanotecnologia. Dentre essas estruturas, destacam-se os nanocarreadores, que permitem melhorar a biodisponibilidade de muitos compostos bioativos, como, por exemplo, o aumento da solubilidade aquosa, melhorando assim processos de absorção e distribuição tecidual (farmacocinética) e também a diminuição de possíveis efeitos tóxicos (redução da toxidade local e sistêmica). ${ }^{1} \mathrm{O}$ desenvolvimento da nanotecnologia permitirá seu uso na produção animal em forma de monitoramento ou mesmo de aplicação direta de produtos nanotecnológicos na saúde, na alimentação, controle de parasitas, conforto térmico e ambiental desses animais. ${ }^{2}$

A nanotecnologia apresenta grande potencial para as pesquisas, possibilitando o desenvolvimento de novos produtos destinados à melhoria da sanidade e saúde animal, o que propicia produtos derivados de animais com maior qualidade e segurança, além de possibilitar potenciais aplicações na área da medicina veterinária, que incluem sistemas de diagnóstico e tratamento de doenças, novas ferramentas para o melhoramento molecular e celular, modificação de resíduos animais, detecção de patógenos, isolamento de toxinas, vetores para o transporte de fármacos, ${ }^{3}$ entre outros. Os avanços da nanotecnologia trazem possíveis consequências econômicas, sociais, ambientais e políticas. ${ }^{4-6}$ A aplicação de nanotecnologia na área veterinária pode auxiliar no desenvolvimento de uma nova

*e-mail: leonardo@sorocaba.unesp.br geração de produtos, como vacinas e métodos de aplicação de produtos veterinários de forma a aumentar a eficácia destes, reduzir possíveis efeitos tóxicos nos animais, bem como reduzir possível contaminação ambiental que o uso continuado destes produtos possa causar.

Algumas nanoformulações têm sido empregadas de forma bem-sucedida para a entrega de fármacos no combate de fungos, protozoários e doenças bacterianas como a candidíase, leishmaniose, salmonelose, brucelose e tuberculose em testes com animais, ${ }^{7}$ demonstrando o grande potencial do uso de nanocarreadores como sistemas de entrega de fármacos e vacinas para o combate de doenças em animais.

A Ivermectina e o Metopreno são amplamente utilizados no controle de endo e ectoparasitas em animais de produção e domésticos. A Ivermectina (IVM) é um composto pertencente ao grupo das lactonas macrocíclicas que foi sintetizada pela primeira vez na década de 1970, no Japão, a partir de fungos Streptomyces avermitilis, sendo assim descoberta uma nova classe, as avermectinas. ${ }^{8} \mathrm{Seu}$ modo de ação contra os parasitas ocorre por meio da estimulação da liberação do neurotransmissor inibidor GABA (ácido gama-aminobutírico) na fenda sináptica entre interneurônios do cordão central e neurônios motores, ${ }^{9,10}$ sendo que quanto maior a liberação de GABA, maior será a hiperpolarização do potencial de repouso normal das células pós-sinápticas, tornando difícil a neurotransmissão dos estímulos para os músculos periféricos. ${ }^{11}$ Desta forma, sob a influência de uma pequena quantidade das avermectinas, os parasitas ficam paralisados, sendo posteriormente expelidos pelo organismo. ${ }^{8} \mathrm{O}$ Metopreno (MTP) é um regulador de crescimento que possui a capacidade de combater uma variedade de espécies de insetos, incluindo Diptera, Lepidoptera, Siphonaptera e Coleoptera, 
o que possibilita ao metopreno uma grande capacidade de controlar uma variedade de pragas. ${ }^{12}$ Reguladores de crescimento de insetos provocam a perturbação nos processos enzimáticos regulados por hormônios que são relativamente específicos para a fisiologia dos insetos. ${ }^{13,14} \mathrm{O}$ Metapreno possui uma rápida degradação na água e em presença de luz, limitando assim em alguns casos o seu uso. Porém, não provoca bioacumulação em peixes e não persiste no ambiente, sofrendo rápida degradação e metabolismo de plantas, animais, micro-organismos aquáticos e de solo. ${ }^{15}$

Devido às características dos dois ativos, o desenvolvimento de produtos e processos mais eficientes destinados ao combate e controle dos efeitos de endo e ectoparasitas em veterinária tem se mostrado necessário. Como possibilidades para aumento da eficácia e estabilidade de fármacos como ivermectina e metopreno, destacam-se os sistemas carreadores lipídicos, no qual se destacam a nanopartícula lipídica sólida e o carreador lipídico nanoestruturado. ${ }^{16-20}$

As nanopartículas lipídicas sólidas (NLS) são sistemas constituídos por lipídeos sólidos sob temperatura ambiente e corporal; ${ }^{16}$ possuem grande importância por apresentarem vantagens como boa estabilidade física, química e biológica, excelente tolerabilidade, boa biodegradação, alta disponibilidade, possibilita a liberação sustentada por possuir uma matriz sólida, permite a prevenção da degradação química ou oxidativa do composto encapsulado, além da possibilidade da metabolização de sua matriz lipídica por diversos organismos. ${ }^{16,19-2.3}$ Sua matriz é composta por lipídeos sólidos em temperatura ambiente, tensoativos e água.

Os carreadores lipídicos nanoestruturados (CLN) foram desenvolvidos como uma segunda geração das NLS, com o objetivo de melhorar a eficiência de encapsulação e o tempo de retenção do fármaco durante o período de armazenamento. ${ }^{18}$ Diferentemente das NLS que são produzidas a partir de lipídios sólidos, os CLN são compostos de uma matriz lipídica sólida encapsulando compartimentos de lipídios líquidos. Uma das vantagens dos CLN em relação às NLS deve-se ao fato de que nos CLN o fármaco não é expulso do interior das nanopartículas, como ocorre nas NLS..$^{19,20}$

Este trabalho tem como principal objetivo preparar e caracterizar sistemas carreadores lipídicos para dois ativos utilizados em aplicações veterinárias, a Ivermectina e o Metopreno, visando o desenvolvimento de formas alternativas para o uso destes para administração por via tópica (pour on). Neste contexto, a nanotecnologia tem um grande potencial para auxiliar na melhora da qualidade de vida animal e no desenvolvimento de soluções para redução de prejuízos econômicos para a pecuária, bem como para a minimização de possíveis impactos ambientais.

\section{PARTE EXPERIMENTAL}

\section{Materiais}

Ivermectina - Pestanal ${ }^{\circledR}$, Metopreno - Pestanal ${ }^{\circledR}$, Ácido Oleico - Sigma ${ }^{\circledR}$, Gliceril Tripalmitato (grau de pureza 85\%) - Sigma ${ }^{\circledR}$, Poli (Álcool Vinílico) - (PVA) - Sigma®, Clorofórmio (grau espectroscópico analítico) - Merck®, Acetonitrila (grau HPLC) - JT Baker ${ }^{\circledR}$, Dispositivos de ultrafiltração de celulose regenerada de 30 kDa- Millipore ${ }^{\circledR}$.

\section{Preparo de nanopartículas lipídicas sólidas e carreadores lipídicos nanoestruturados}

As NLS e CLN foram preparadas utilizando o processo de emulsão/evaporação de solvente, adaptado de Vitorino et al..$^{24}$ Inicialmente, foi preparada uma solução de $30 \mathrm{~mL}$ contendo água deionizada com $1,25 \%$ de poli (álcool vinílico), polímero semicristalino utilizado como tensoativo, a qual foi mantida sob agitação. Em seguida, $250 \mathrm{mg}$ de tripalmitina foram dissolvidos em $5 \mathrm{~mL}$ de clorofórmio. Nesta mesma fase orgânica foram adicionados $10 \mathrm{mg}$ de IVM ou $10 \mathrm{mg}$ de MTP, e então a fase orgânica foi gotejada com o auxílio de uma ponteira na fase aquosa. Esta solução foi então submetida à sonicação durante 5 minutos em sonicador com $40 \mathrm{~W}$ de potência resultando em uma pré-emulsão. Posteriormente, essa pré emulsão foi levada a um ultraturrax, onde foi agitada vigorosamente por 7 minutos a uma velocidade de $14000 \mathrm{rpm}$. Após a agitação foi realizado o processo de evaporação do solvente orgânico, o qual foi eliminado com o auxílio de um evaporador rotativo, e a emulsão foi concentrada até o volume final de $10 \mathrm{~mL}$, obtendo-se NLS com a concentração final de $1 \mathrm{mg}$ $\mathrm{mL}^{-1}$ de IVM ou MTP

Para o preparo de CLN, procedeu-se da mesma forma como descrito para NLS, porém, em vez de utilizar $250 \mathrm{mg}$ de tripalmitina, utilizou-se $125 \mathrm{mg}$ de tripalmitina e $125 \mathrm{mg}$ de ácido oleico.

\section{Medidas de caracterização e estabilidade das formulações}

\section{Medida de diâmetro médio de partículas por espectroscopia de correlação de fótons}

A avaliação da distribuição de tamanho das nanopartículas foi realizada diluindo-se as suspensões de partículas com água deionizada (1:1000 v:v) e empregando um analisador de partículas ZetaSizer Nano ZS 90 (Malvern) sob um ângulo fixo de $90^{\circ} \mathrm{e}$ temperatura de $25^{\circ} \mathrm{C}$. Cada resultado foi expresso como medida de três determinações, sendo aplicada análise estatística de variância (ANOVA) com o teste de Tukey-Kramer através do software GraphPad Prism v.6 ${ }^{\circledR}{ }^{25-27}$

\section{Potencial Zeta}

A carga das partículas foi avaliada através da determinação de potencial zeta, utilizando-se um analisador de potencial zeta Zetasizer Nano ZS 90 (Malvern). As avaliações foram efetuadas diluindo-se as suspensões em água deionizada (1:1000 v:v) e os resultados foram expressos como médias de três determinações.

\section{Estabilidade lipídica $(\mathrm{pH})$}

Monitorar o pH de suspensões coloidais em função do tempo traz informações relevantes para indicar a estabilidade química dos componentes da formulação. Variações no $\mathrm{pH}$ das formulações podem indicar alterações nestes componentes que podem ser devido à hidrólise química de grupos funcionais presentes nos componentes das formulações. ${ }^{28} \mathrm{O}$ pH das suspensões de nanopartículas lipídicas sólidas foi medido no decorrer de 120 dias e utilizou para isso um medidor de $\mathrm{pH}$ (Jenway ${ }^{\circledR}$, modelo 3510) previamente calibrado com soluções tampão em pH 7,0 e 4,0.

\section{Rastreamento de nanopartículas}

Para as análises de rastreamento de nanopartículas, os dados foram coletados por meio de uma célula NanoSight LM 10 (laser verde, $532 \mathrm{~nm}$ ) e uma câmera sCMOS usando software NanoSight (versão 2.3). Para evitar a contaminação das amostras, medições da água deionizada foram realizadas. As suspensões de nanopartículas foram diluídas 30000 vezes, sendo feitas análises em triplicata para cada amostra. Para garantir que diferentes partículas fossem analisadas, para cada réplica, $1 \mathrm{~mL}$ de suspensão da amostra foi injetado na célula volumétrica, com o intuito de deslocar o conteúdo medido anteriormente. Cada repetição foi constituída de cinco medições com aproximadamente 2000 partículas contadas em cada análise. Foi obtida como resultado final a distribuição de tamanho das partículas em função da concentração, os quais foram expressos com o desvio padrão. ${ }^{29}$ 


\section{Microscopia Eletrônica de Transmissão}

A morfologia das NLS e CLN foi verificada por Microscopia Eletrônica de Transmissão (Zeiss-LEO 906) conforme o método previamente descrito. ${ }^{30}$ Uma pequena alíquota da suspensão de nanopartículas foi colocada em grades de cobre de 200 malhas por 15 min. Uma solução de acetato de uranila à $2 \%$ foi utilizada como contraste, sendo esta gotejada sobre a grades e posterior remoção do excesso utilizando um papel. Após o preparo das amostras, as mesmas foram analisadas no microscópio a uma voltagem de $80 \mathrm{kV}$.

\section{Eficiência de retenção dos ativos nas formulações}

A quantidade do bioativo retido nas nanopartículas foi determinada pelo método de ultrafiltração/centrifugação, que se baseia em submeter a suspensão de nanopartículas à centrifugação em dispositivos de ultrafiltração constituídos de celulose regenerada de $10 \mathrm{kDa}$ (Microcon - Millipore ${ }^{\circledR}$ ) e quantificar o ultrafiltrado por cromatografia líquida de alta eficiência (CLAE). ${ }^{28,31,32}$

A eficiência de retenção (\% ER) foi determinada através da equação (1):

$$
\% E R=\frac{A}{B} \times 100
$$

em que A corresponde a quantidade do ativo encapsulada nas partículas e $\mathrm{B}$ a quantidade total inicial de ativo adicionada às formulações.

\section{Ensaio de liberação in vitro}

Com o propósito de verificar o perfil de liberação dos ativos pelas nanopartículas foi realizado ensaio de cinética de liberação. A liberação dos fármacos (IVM e MTP) através das nanopartículas foi modificado baseando-se no método descrito por Asrar et al. ${ }^{33} \mathrm{Os}$ ensaios foram realizados em condição de diluição "sink". ${ }^{34}$ Sendo assim, 0,7 mL da suspensão de nanopartículas contendo IVM, de solubilidade em meio aquoso de $4 \mathrm{mg} \mathrm{L}^{-1}$, foi diluído em $700 \mathrm{~mL}$ de agua deionizada, enquanto $0,3 \mathrm{~mL}$ da suspensão de nanopartículas contendo MTP, de solubilidade em meio aquoso de $0,51 \mathrm{mg} \mathrm{L}^{-1}$, foi diluído em $857 \mathrm{~mL}$ de água deionizada. Alíquotas de $10 \mathrm{~mL}$ destas misturas foram então colocadas em tubos Falcon fechados e submetidas à agitação em shaker (150 rpm) em temperatura ambiente. Em períodos de 15, 30, 45 e 60 min, ao longo de 180 minutos, um tubo era removido do shaker, submetido à centrifugação para a sedimentação das nanopartículas, e o sobrenadante era filtrado através de um filtro de 0,45 $\mu \mathrm{m}$ e quantificado por CLAE. Os valores de área obtidos foram convertidos em concentração de ativo em $\mu \mathrm{g} \mathrm{mL}{ }^{-1}$, utilizando como padrão uma solução dos ativos livres. As medidas foram realizadas em triplicata.

\section{Ensaio de cito e genotoxicidade}

\section{Citotoxicidade - Teste de redução do tetrazolium MTT (Método colorimétrico)}

Os testes de viabilidade celular foram realizados em células da linhagem 3T3 (fibroblastos de camundongos Balb-c 3T3) e V79 (fibroblastos pulmonares de Hamster), mantidas em cultura contínua em meio de cultura DMEM suplementado com $10 \%$ de soro fetal

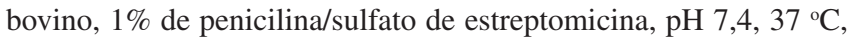
sob atmosfera úmida com $5 \%$ de $\mathrm{CO}_{2}$. O plaqueamento foi realizado inoculando-se $1 \times 10^{4}$ células por poço em placas de 96 poços, incubadas por 24 horas até a aderência. Após a aderência as células foram expostas durante 24 horas às formulações de nanopartículas incorporadas ou não com ativos em concentrações variando na faixa de 0 a $50 \mu \mathrm{g} \mathrm{mL}^{-1}$. A viabilidade celular foi determinada através do teste de redução do 3(4-5 dimetiltiazol-2-il)-2,5-brometo de difeniltetrazólico (MTT). As células foram incubadas com MTT $(0,5$ $\mathrm{mg} \mathrm{mL} \mathrm{m}^{-1}$ ) durante 3 horas a $37^{\circ} \mathrm{C}$. O número de células viáveis foi determinado através da medição da quantidade de MTT convertido a formazan (composto púrpura) pelas desidrogenases mitocondriais. Os cristais de formazan formados foram dissolvidos em DMSO à temperatura ambiente. A absorbância da solução em cada cavidade foi medida em leitor de placas (Labsystems Multiskan MS) em 570 $\mathrm{nm}$ e calculou-se as porcentagens de células viáveis. ${ }^{35,36}$

\section{Ensaio de aberração cromossômica Allium cepa}

O ensaio de genotoxicidade foi realizado utilizando-se sementes de Allium cepa, no qual 30 sementes foram colocadas para germinar em placa de Petri contendo água destilada. Ao atingirem o tamanho entre 15 e $20 \mathrm{~mm}$ foram utilizadas para o teste. As raízes foram retiradas e expostas por $24 \mathrm{~h}$ às formulações de nanopartículas sem e contendo os fármacos, sem serem diluídas. Em seguida, foram fixadas em fixador de Carnoy durante 24 h. Após a fixação, foram removidas da solução fixadora e lavadas por três vezes com água destilada para remoção do excesso de fixador. Posteriormente, foram submetidas à hidrólise ácida a $60{ }^{\circ} \mathrm{C}$, em que as raízes foram colocadas em banho maria a $60{ }^{\circ} \mathrm{C}$ durante 9 minutos em uma solução de $\mathrm{HCl} 1 \mathrm{~mol} \mathrm{~L}{ }^{-1}$. Após esta etapa, as raízes foram retiradas do banho e lavadas com água destilada por aproximadamente 5 minutos cada uma, e colocadas em reativo de Schiff durante $2 \mathrm{~h}$ para coloração. Após esse tempo, as raízes passaram por 3 banhos de água destilada até ser retirado todo o excesso do corante. Cortou-se a região meristemática das raízes que foram colocadas em lâmina com uma gota de Carmim Acético $2 \%$ (corante citoplasmático) e, em seguida, colocou-se a lamínula e executou-se suavemente o esmagamento para espalhar as células. Após o preparo das lâminas realizou-se a observação ao microscópio com a contagem e classificação das células.

Para este estudo utilizou-se amostras dos ativos (IVM e MTP) e dos nanocarreadores (NLS e CLN) incorporadas ou não com ativos nas concentrações de $1 \mathrm{mg} \mathrm{mL}{ }^{-1}$. Como controle, utilizou-se água destilada. O teste de genotoxicidade foi realizado em triplicata, sendo aplicada análise estatística de variância (ANOVA) com o teste de Tukey-Kramer através do software GraphPad Prism v.6 ${ }^{\circledR}$.

\section{RESULTADOS E DISCUSSÃO}

\section{Caracterização dos sistemas lipídicos}

As análises de distribuição de tamanho para as nanopartículas mostraram o perfil monomodal das mesmas, ou seja, a existência de apenas uma população de nanopartículas, tanto na análise de NLS como de CLN. Isto é de grande importância, pois se busca em formulações para liberação modificada uma maior homogeneidade do sistema, para que ocorram menores interferências no processo de liberação dos ativos. ${ }^{12,25,37}$

A Figura 1 retrata a distribuição de tamanho de NLS na ausência e na presença dos fármacos IVM e MTP no tempo inicial de estabilidade (0 dias), no tempo intermediário (60 dias) e no tempo final (120 dias). Observa-se (Figura 1a) que não houve alteração significativa de tamanho durante o período de estocagem. Este perfil de distribuição foi semelhante para as NLS contendo MTP (Figura 1c), no entanto, para o tempo de 120 dias pode-se observar o aparecimento de uma população com tamanho ao redor de $1000 \mathrm{~nm}$, podendo indicar a presença de algum fenômeno de agregação. Para as NLS contendo IVM (Figura 1b) pode-se observar uma pequena alteração no perfil de distribuição de tamanho da formulação. Pode-se observar que durante o tempo de estocagem ocorreu variação na intensidade do tamanho da partícula analisada, o que sugere uma possível formação de agregados. 

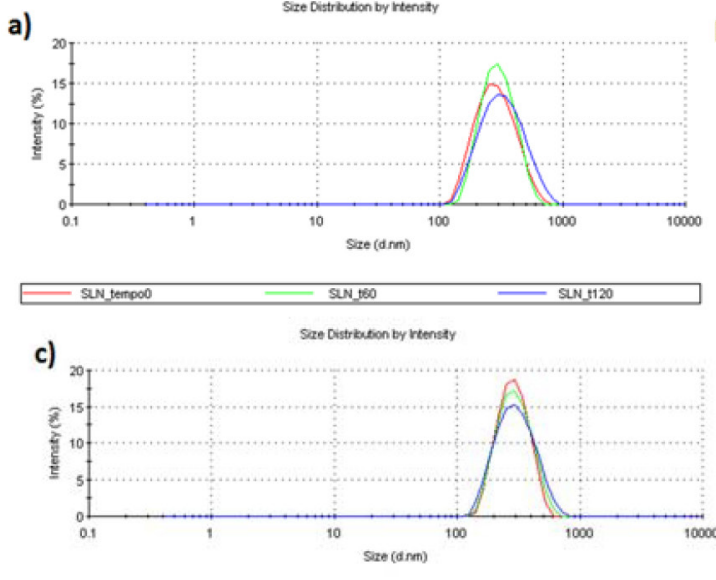

SLNMTP HTO b)

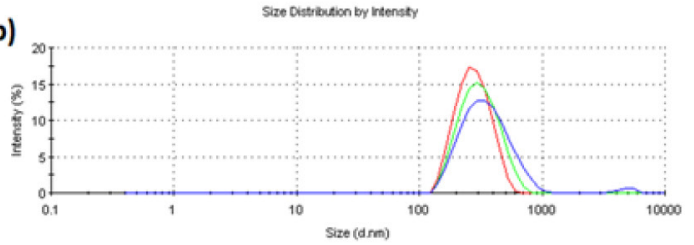

- $\sin \sin 100$
SLN_Mm 560

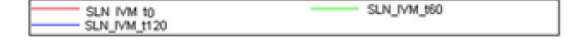

Figura 1. Distribuição de tamanho de NLS para os tempos 0, 60 e 120 dias na ausência de fármacos (a), contendo IVM (b) e contendo MTP (c)

A Figura 2a apresenta a variação do tamanho médio das formulações de nanopartículas lipídicas sólidas (NLS) com e sem os ativos IVM e MTP.

Como observado nas Figuras 1 e 2a, as formulações de NLS sem os ativos e com os ativos apresentaram estabilidade durante o período estudado, apesar de sofrerem alterações significativas em seu tamanho médio: na formulação de NLS com IVM ocorreram alterações significativas em seu tamanho no período de estudo, sendo
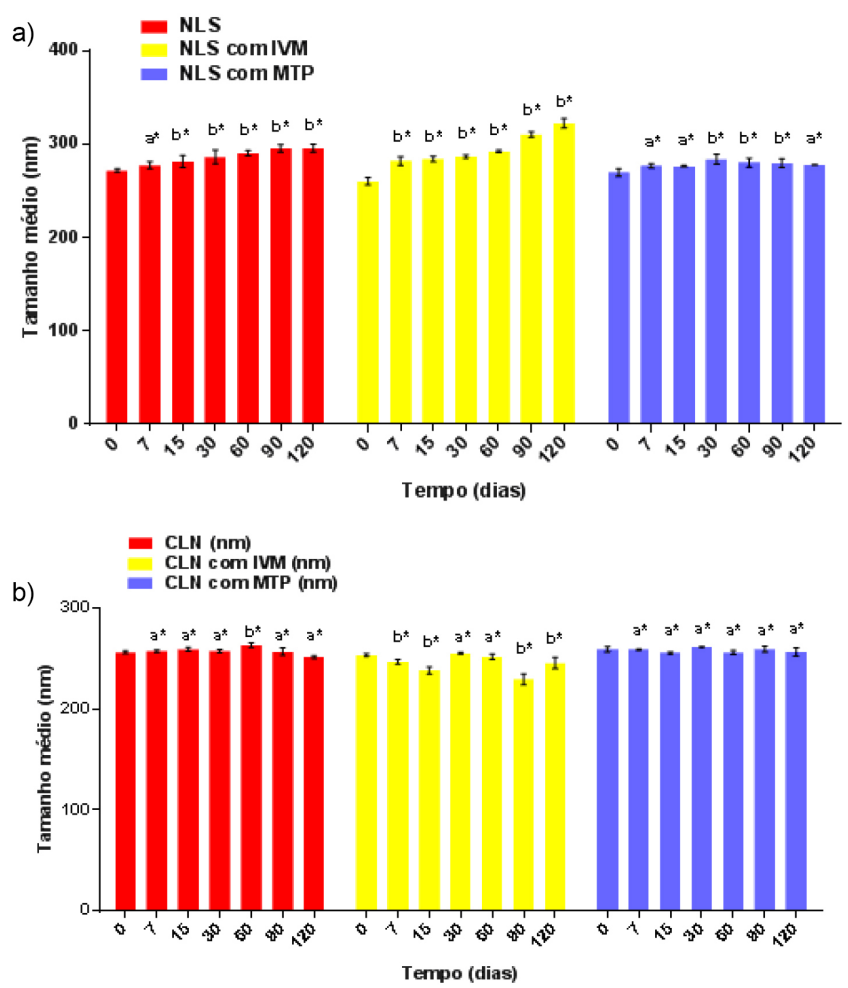

Figura 2. a) Tamanho médio das NLS com e sem IVM e MTP em função do tempo. As medidas foram realizadas em triplicada $(n=3)$. b) Tamanho médio dos CLN com e sem IVM e MTP em função do tempo. Utilizou-se o teste ANOVA para verificação de alterações significativas, sendo considerada uma significância de $p<0,05$ para as diferenças estatísticas observadas entre os grupos, onde a* representa variações não significativas entre os grupos em função do tempo em relação ao controle no tempo zero; $b^{*}$ representa variações significativas entre os grupos em função do tempo em relação ao controle no tempo zero observadas estas alterações em todo o decorrer de estocagem. Este aumento no tamanho pode estar associado à possível formação de agregados. As formulações de NLS contendo MTP apresentaram alterações significativas a partir de 30 dias de estocagem. De modo geral, o diâmetro das formulações de NLS, NLS com IVM e NLS com MTP foi de 285,6 nm; 291,3 nm e 277,9 nm, respectivamente.

A Figura $2 b$ apresenta a variação do tamanho médio das formulações de carreadores lipídicos nanoestruturados (CLN) com e sem os ativos ivermectina (IVM) e metopreno (MTP). Como observado na Figura $2 b$, as formulações de CLN sem os ativos não apresentaram alterações significativas durante o período de estocagem, exceto no tempo de 60 dias. As formulações contendo MTP também não apresentaram alterações significativas durante o tempo de estudo. As formulações de CLN com IVM apresentaram alterações significativas de tamanho durante o período de estocagem. De modo geral, as formulações apresentaram tamanho médio geral de 257,5; 245,9 e 258,3 nm para as formulações de CLN, CLN com IVM e CLN com MTP, respectivamente.

Observa-se que tanto as formulações de NLS como as de CLN apresentaram no tempo inicial um tamanho médio abaixo de $300 \mathrm{~nm}$, destacando a eficiência do método de preparo das partículas. Pode-se observar também que as formulações de NLS apresentaram maior tamanho quando comparadas às formulações de CLN. Isso pode ter ocorrido pelo fato de que os CLN são formados por lipídios sólidos e líquidos, enquanto as NLS são formadas apenas por lipídio sólido. Lipídios com ponto de fusão mais elevados podem originar um aumento no tamanho das nanopartículas. ${ }^{38}$ Como o ácido oleico apresenta ponto de fusão menor que a tripalmitina e os CLN apresentam $50 \%$ da massa de tripalmitina presente nas NLS, as formulações de CLN apresentam menores tamanhos durante o período de estocagem, como observa-se nas Figuras 1 e $2 b$.

A polidispersão também foi analisada durante o período de estudo. A polidispersão representa a variabilidade do tamanho da partícula. Nas Figuras 3 estão representadas as variações de polidispersão das formulações de NLS e CLN com e sem IVM e MTP.

Observa-se nas Figuras 3 a e b a ocorrência de variações na polidispersão em função do tempo. Estas variações podem estar relacionadas à reorganização na distribuição de tamanho das partículas durante o período de armazenagem, porém, todas as formulações apresentaram valores abaixo de 0,2 , o que evidencia boa estabilidade das formulações. A polidispersão média das formulações de NLS, NLS com IVM, NLS com MTP, CLN, CLN com IVM e CLN com MTP foi $0,130 \pm 0,045 ; 0,164 \pm 0,059 ; 0,119 \pm 0,048 ; 0,100 \pm 0,06 ; 0,097 \pm 0,061 \mathrm{e}$ $0,109 \pm 0,048$, respectivamente. Estes resultados demonstram que as 

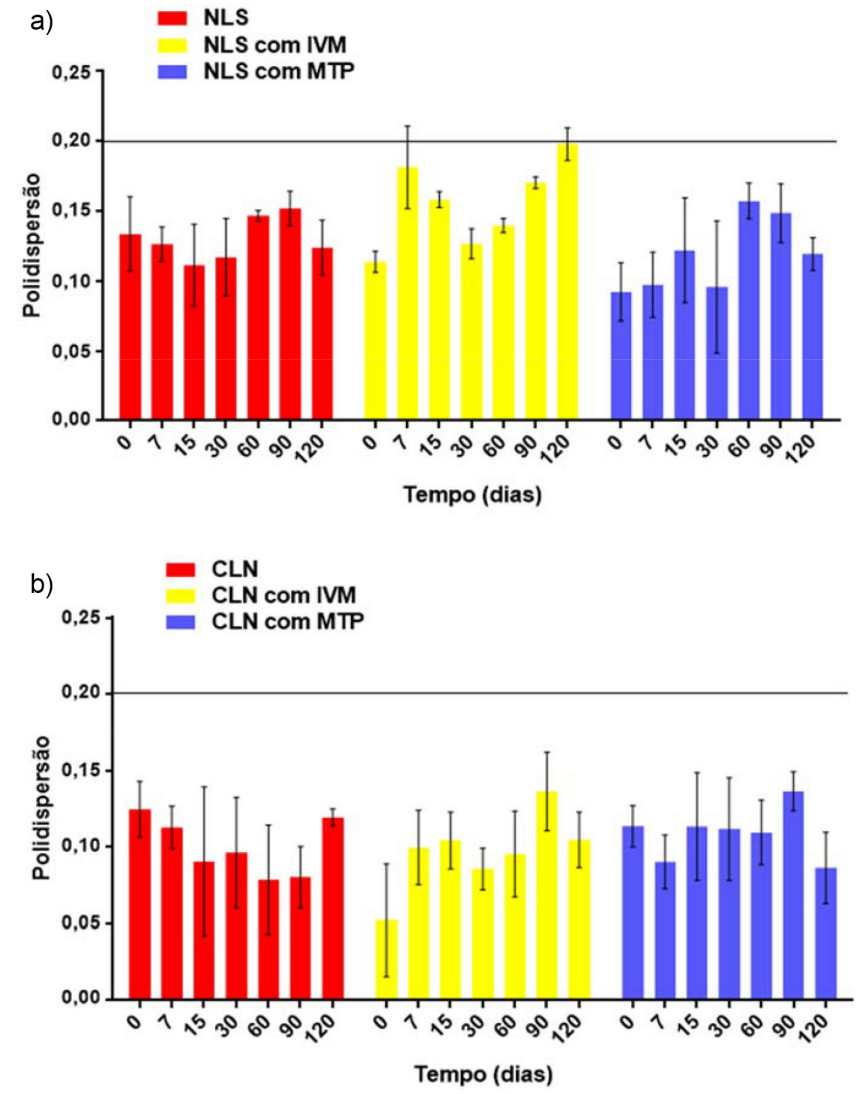

Figura 3. Polidispersão média de a) NLS e b) CLN com e sem IVM e MTP em função do tempo

formulações de nanopartículas na ausência ou presença dos fármacos IVM e MTP apresentam boa estabilidade.

Assim como o tamanho, a polidispersão sofre aumento quando comparamos os valores das formulações de CLN com as de NLS.
Um acréscimo de 5-10\% no volume lipídico gera partículas de maior tamanho e uma distribuição mais ampla do tamanho das partículas, ou seja, um acréscimo no valor do índice de polidispersão. ${ }^{39}$

\section{Rastreamento de nanopartículas}

A técnica de rastreamento de nanopartículas foi utilizada para caracterizar as suspensões de NLS e CLN. As análises de distribuição de tamanho das partículas são apresentadas na Figura 4. No tempo inicial (0 dias), observa-se que para as NLS (Figura 4) na ausência dos ativos foi obtido um diâmetro hidrodinâmico de

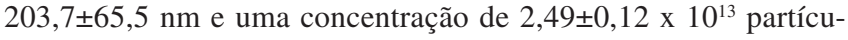
las por mL. Para as NLS contendo os ativos IVM e MTP foram obtidos diâmetro médios de 237,3 $\pm 83,6 \mathrm{~nm}$ e $185,1 \pm 98,3 \mathrm{~nm}$, e concentração de 4,32 $\pm 0,3 \times 10^{13}$ e $7,47 \pm 1,14 \times 10^{13}$ partículas por $\mathrm{mL}$, respectivamente. Para os CLN na ausência dos ativos, o diâmetro médio apresentado foi de $191,1 \pm 52,2 \mathrm{~nm}$ e concentração de $5,43 \pm 0,06 \times 10^{13}$ partículas por $\mathrm{mL}$. Para os CLN com os ativos IVM e MTP o diâmetro médio apresentado foi de $196,5 \pm 87,1$ $\mathrm{nm}$ e $196,3 \pm 62,3 \mathrm{~nm}$, e a concentração foi de 4,35 $\pm 0,3 \times 10^{13}$ e $4,53 \pm 0,09 \times 10^{13}$ partículas por $\mathrm{mL}$, respectivamente.

Para o tempo de 120 dias (dados não mostrados), para as NLS na ausência dos ativos foi obtido um diâmetro médio de $258,2 \pm 170,6 \mathrm{~nm}$ e concentração de $5,31 \pm 3,18 \times 10^{13}$ partículas por $\mathrm{mL}$, respectivamente. Para as NLS contendo os ativos IVM e MTP, foram obtidos diâmetro médios de 193,7 $\pm 63,4 \mathrm{~nm}$ e 188,6 $\pm 76,3 \mathrm{~nm}$, e concentração de $2,10 \pm 0,15 \times 10^{13}$ e $2,35 \pm 0,09 \times 10^{13}$ partículas por $\mathrm{mL}$. Para os CLN na ausência dos ativos o diâmetro médio encontrado foi de $193,1 \pm 78,2 \mathrm{~nm}$ e concentração de 1,68 $\pm 0,05$ $\mathrm{x} 10^{13}$ partículas por $\mathrm{mL}$. Para os CLN com os ativos IVM e MTP, o diâmetro médio encontrado foi de $167,8 \pm 75,9 \mathrm{~nm}$ e 222,3 297,7 nm e concentração de 4,32 $\pm 0,6 \times 10^{13}$ e $3,18 \pm 0,24 \times 10^{13}$ partículas por $\mathrm{mL}$, respectivamente.

Como se pode observar (Figura 2 e Figura 4), por ambas as técnicas (espectroscopia de correlação de fótons e rastreamento de partículas) foram obtidos valores semelhantes para a distribuição de tamanho. Eventuais diferenças podem ser devido à forma de
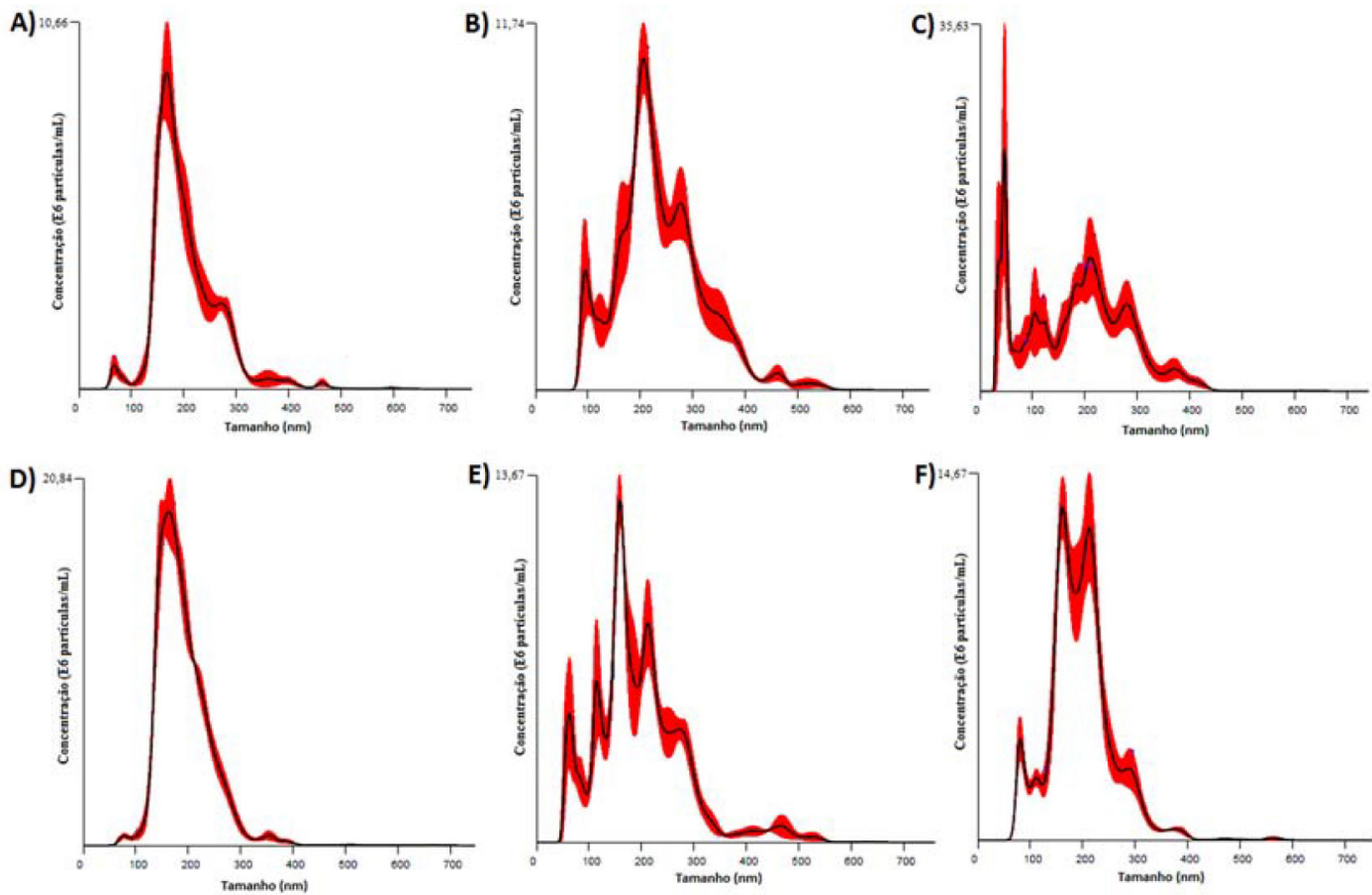

Figura 4. Distribuição de tamanho das partículas em função da concentração no tempo de 0 dias. A) NLS; B) NLS contendo IVM; C) NLS contendo MTP; D) $C L N$; E) CLN contendo IVM; F) CLN contendo MTP. As análises foram realizadas a $25^{\circ} \mathrm{C}$. A linha vermelha é correspondente ao desvio padrão das análises 
realização de análises, em especial em relação a questão de diluição das amostras. No NTA as amostras são diluídas em 30.000 vezes enquanto na ECF a diluição é realizada em 1.000 vezes. Tais diferenças em diluições podem fazer com que eventuais agregados sejam desfeitos e isso faz com que em geral os valores de NTA sejam menores que os observados por ECF.

\section{Potencial Zeta}

A Figura 5 (a e b) apresenta os valores do potencial zeta para as formulações de NLS e CLN com e sem os fármacos. As formulações apresentaram valores médios de potencial zeta de -18,1; -14,7; -15,6; $-18,8 ;-20,9$; e -20,7mV para NLS, NLS com IVM, NLS com MTP, CLN, CLN com IVM e CLN com MTP, respectivamente.

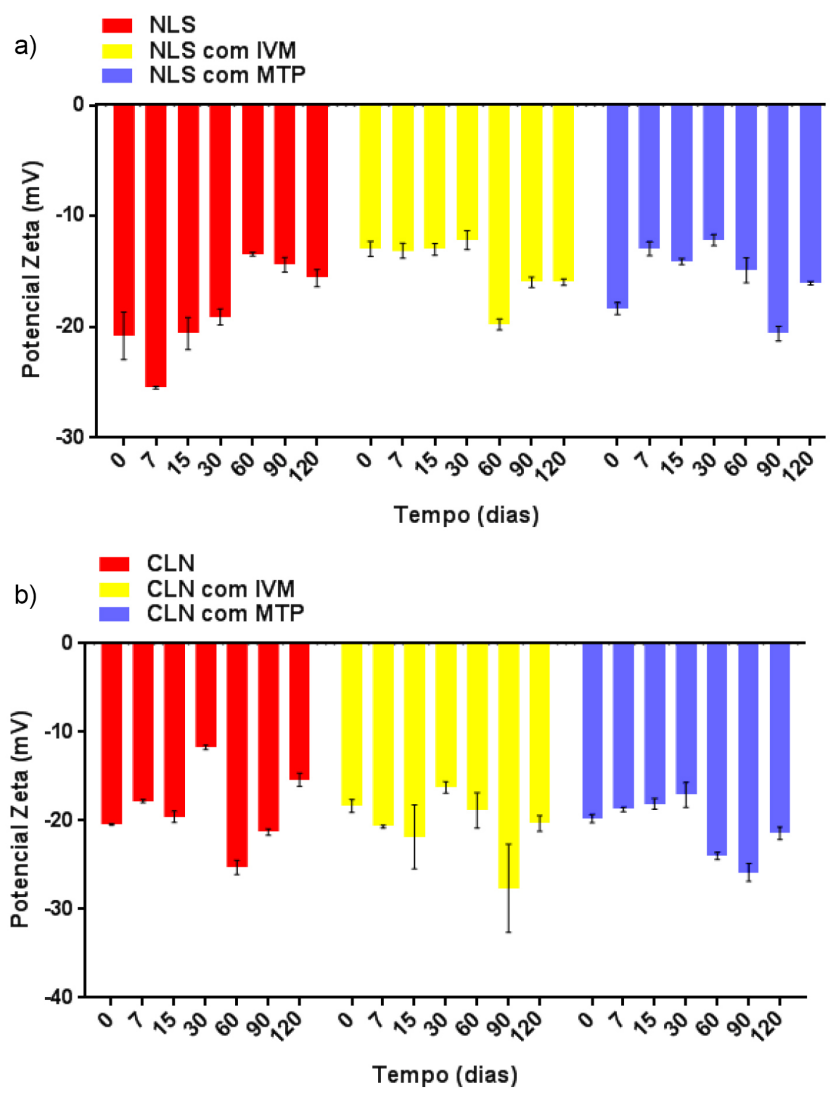

Figura 5. Potencial zeta de a) NLS e b) CLN com e sem IVM e MTP em função do tempo de 120 dias

No preparo das formulações, utilizou-se álcool polivinílico como tensoativo e este, por sua vez, possui uma ação estabilizante, ou seja, adsorve sobre a superfície das partículas criando uma camada estabilizadora por efeito estérico, a qual leva a uma redução do potencial zeta medido. ${ }^{40,41}$ Desta forma, o principal fator de estabilização destas partículas é determinado pela presença do tensoativo e não pelo valor do potencial zeta. Assim, os valores de potencial zeta nessas formulações não indicam, necessariamente, uma baixa estabilidade. Mesmo com o efeito estabilizante do PVA, pode-se observar que, em função do tempo para os dois carreadores (contendo ou não os ativos), não foram observadas grandes alterações nos valores de potencial zeta, sendo os valores entre $-14 \mathrm{mV}$ e $-25 \mathrm{mV}$.

$p H$

$\mathrm{O}$ pH foi um dos parâmetros investigados para avaliar a estabilidade das NLS e dos CLN na presença e ausência dos fármacos. Na Figura 6 está representada as variações de $\mathrm{pH}$ das formulações com e sem os ativos IVM e MTP. Pode-se observar que ocorreram pequenas variações de $\mathrm{pH}$ nas formulações durante o tempo de armazenagem de 120 dias. Constata-se também que as formulações de NLS apresentaram uma tendência de aumento no valor do $\mathrm{pH}$ enquanto as formulações de CLN apresentaram uma tendência de diminuir o valor do $\mathrm{pH}$. Estas alterações podem estar relacionadas à composição da fase lipídica de cada formulação e pode indicar uma possível degradação dos fármacos ou dos componentes das formulações devido à hidrólise química de grupos funcionais presentes nos componentes das formulações. ${ }^{28}$
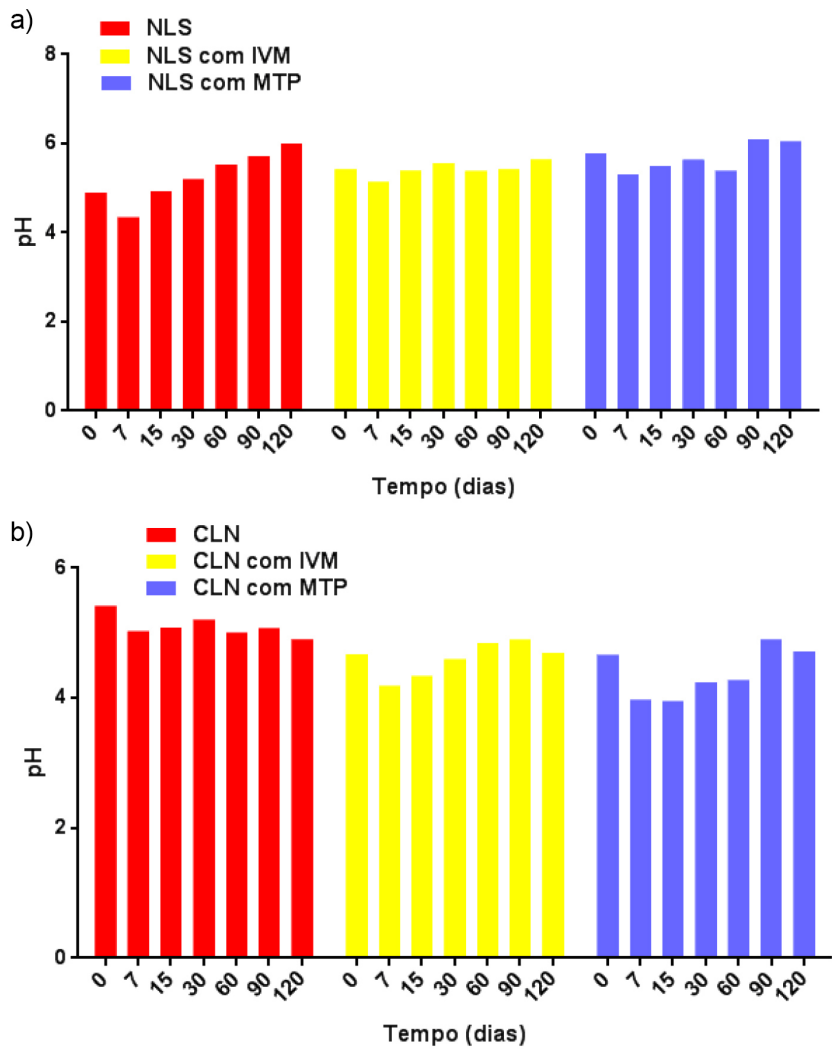

Figura 6. pH das a) NLS e b) CLN com e sem IVM e MTP em função do tempo de 120 dias

As formulações de NLS sofreram diminuição na variação de pH quando ocorreu a encapsulação dos ativos comparando-se com a nanopartícula na ausência destes. As formulações de CLN não apresentaram grandes alterações de $\mathrm{pH}$ entre as nanopartículas com os ativos encapsulados e na ausência destes.

\section{Eficiência de retenção}

A porcentagem dos ativos retidos foi determinada através da quantificação da porcentagem dos ativos IVM e MTP não encapsulados, livres no ultrafiltrado após a ultrafiltração, usando-se a equação 1. As porcentagens de retenção para a IVM nas NLS e CLN foram de $99,90 \pm 0,02 \%$ e $99,90 \pm 0,01 \%$ respectivamente. Para o MTP os valores encontrados foram $99,85 \pm 0,02$ para NLS e $99,84 \pm 0,02 \%$ para CLN.

Os valores indicam que a afinidade entre os ativos com os sistemas nanoestruturados lipídicos é alta, sendo que tal fato se deve principalmente pela hidrofobicidade destes compostos e também por suas baixas solubilidades em meio aquoso (IVM $=4 \mathrm{mg} \mathrm{L}^{-1} \mathrm{e}$ MTP $=0,51 \mathrm{mg} \mathrm{L}^{-1}$ ). Além disso, destaca-se o fato dos valores de coeficiente de partição da IVM (log Poctanol-água = 3,21) e MTP ( $\log$ Poctanol-água $=5,50$ ), indicando assim uma alta interação com a fase lipídica. ${ }^{42,43}$ 


\section{Ensaio de liberação dos ativos}

A liberação dos ativos está diretamente relacionada com a estrutura dos carreadores, bem como a interação do ativo com o sistema carreador. Os resultados se encontram na Figura 7.
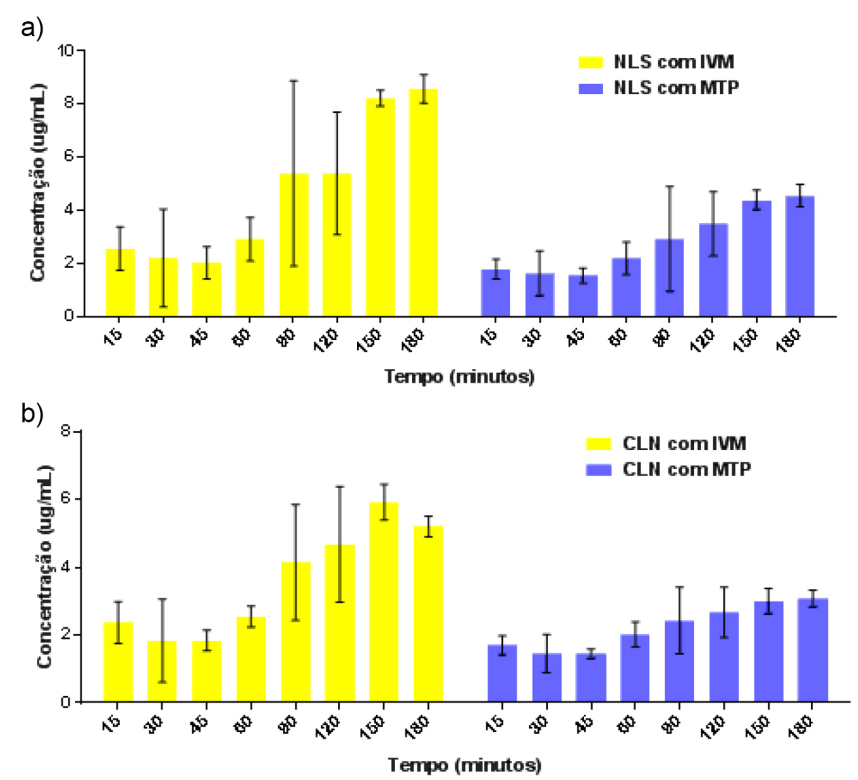

Figura 7. Ensaio de liberação in vitro dos ativos IVM e MTP das partículas de a) NLS e b) CLN em função do tempo de 180 minutos

Como observado nas Figuras 7a e b, as formulações de NLS e CLN contendo os fármacos apresentam uma liberação lenta. Comparando as formulações em teste, tanto nas NLS como nos CLN, a IVM é liberada mais rapidamente que o MTP e a liberação das NLS é maior que a dos CLN. Este fato provavelmente é devido às interações existentes entre os ativos e os componentes dos sistemas carreadores, o que também pode explicar o fato de que a liberação dos ativos ocorre de forma lenta, uma vez que, assim como descrito na literatura, alguns fármacos possuem maior solubilidade em lipídios líquidos do que em lipídios sólidos, proporcionando um menor grau de expulsão do fármaco. ${ }^{44,45}$ Outro aspecto que pode ser destacado para a liberação mais rápida da IVM em relação ao MTP deve-se aos valores de coeficiente de partição octanol-água da IVM $(\log P$ 3,21) ser menor que o do MTP $(\log P 5,50)$. Destaca-se que tais valores provavelmente se devem às características dos grupamentos presentes nas moléculas destes compostos, sendo que a IVM possui um maior número de grupamentos capazes de formar ligações de hidrogênio com a água em relação à molécula de MTP.

\section{Microscopia eletrônica de transmissão (MET)}

A técnica de MET foi empregada para caracterizar a morfologia das nanopartículas NLS e CLN contendo os ativos IVM e MTP, sendo avaliadas no tempo inicial de estocagem (Figura 8).

Como se pode observar nas micrografias obtidas, todas as nanopartículas apresentam formato esférico. A Figura 8 apresenta a micrografia de NLS no tempo de 0 dias contendo IVM (a) e MTP (b), e CLN no tempo de 0 dias contendo os ativos IVM (c) e MTP (d) com aumento de 27800 vezes. A partir da figura pode-se observar ainda que as nanopartículas (NLS e CLN) apresentam aproximadamente o mesmo tamanho e formato esférico, havendo formação de uma segunda população na formulação de CLN contendo MTP, sem ocorrer alteração das características morfológicas das nanopartículas.
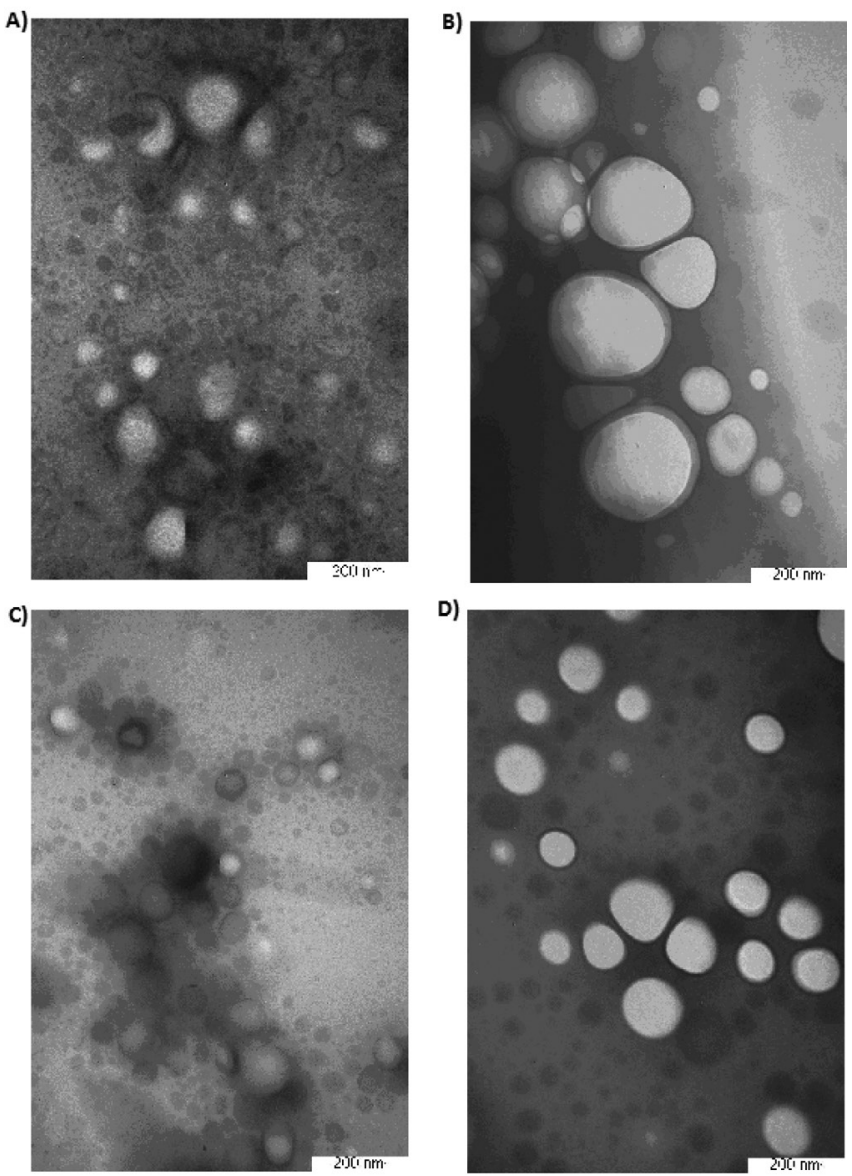

Figura 8. Micrografias de A e B) NLS e C e D) CLN no tempo de 0 dias contendo IVM (a) e MTP (b), e CLN no tempo de 0 dias contendo os ativos IVM (c) e MTP (d) com aumento de 27800 vezes

\section{Ensaios de cito e genotoxicidade}

\section{Ensaio de citotoxicidade - Teste de redução do tetrazolium MTT (método colorimétrico)}

Foram utilizados dois tipos celulares para verificar possíveis variações entre diferentes células, sendo utilizadas células do tipo $3 \mathrm{~T} 3$ e células V79. A Figura 9a apresenta os resultados para os ensaios de viabilidade celular, nos quais foram avaliados os efeitos citotóxicos dos fármacos IVM e MTP, das NLS e CLN contendo os fármacos IVM e MTP e também das NLS e CLN na ausência destes utilizando-se linhagem de células 3T3.

A Figura $9 \mathrm{~b}$ apresenta os resultados para os ensaios de viabilidade celular, nos quais foram avaliados os efeitos citotóxicos dos fármacos IVM e MTP, das NLS e CLN contendo os fármacos IVM e MTP e também das NLS e CLN na ausência destes utilizando-se células V79.

A Tabela 1 apresenta os valores de $\mathrm{IC}_{50}$ para os ativos (IVM e MTP) e também para as formulações de NLS e CLN na ausência e contendo esses ativos para as células 3T3 e V79.

Os resultados demonstram que as nanopartículas testadas para a encapsulação possibilitaram a alteração na viabilidade celular das células testadas. Porém, as nanopartículas sem a presença dos ativos apresentaram citotoxicidade na faixa de concentração estudada, uma vez que não mantiveram a viabilidade celular em torno de $100 \%$ para as concentrações analisadas. Observa-se nas Figuras 9a (células 3T3) e 9b (células V79) que as NLS apresentam menor toxicidade que os CLN, dado que o valor de $\mathrm{IC}_{50}$ de NLS é maior que o de CLN. Quando ocorre a encapsulação, este fato se mantém, sendo que as formulações de NLS encapsulada com os ativos IVM ou MTP apresentam menor 

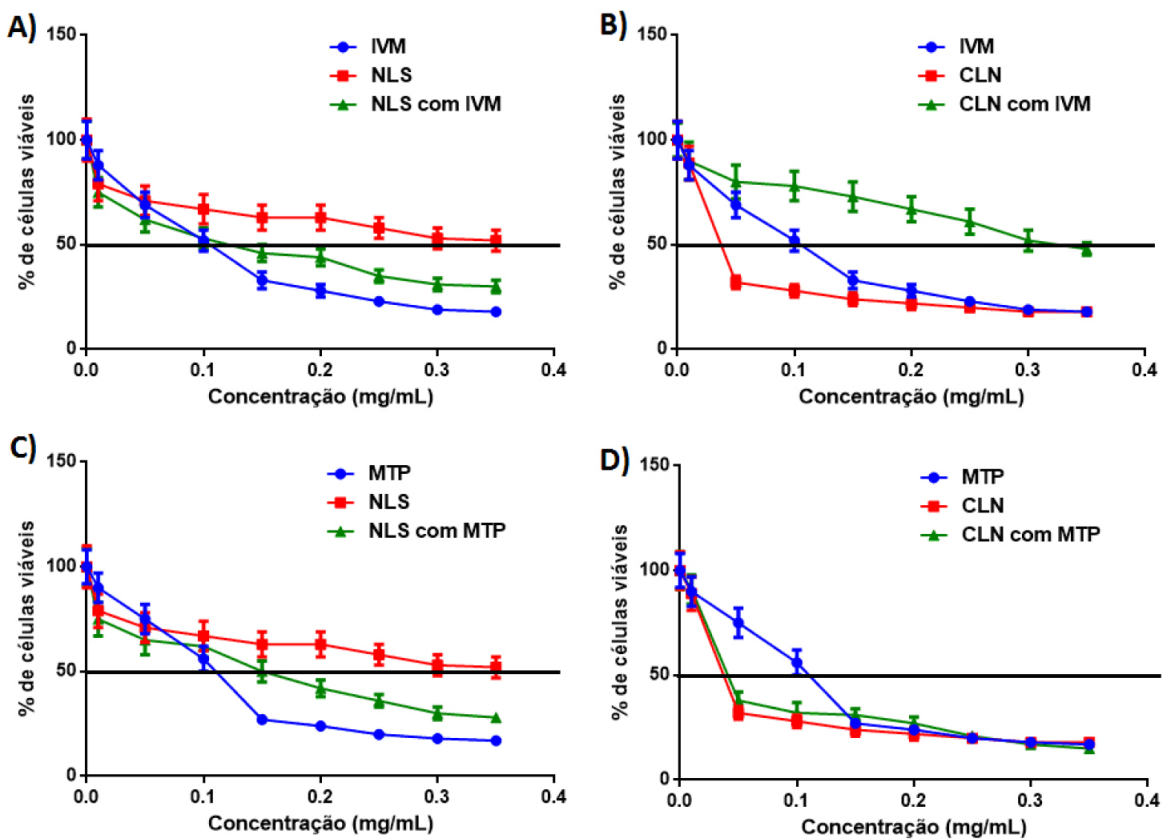

V79
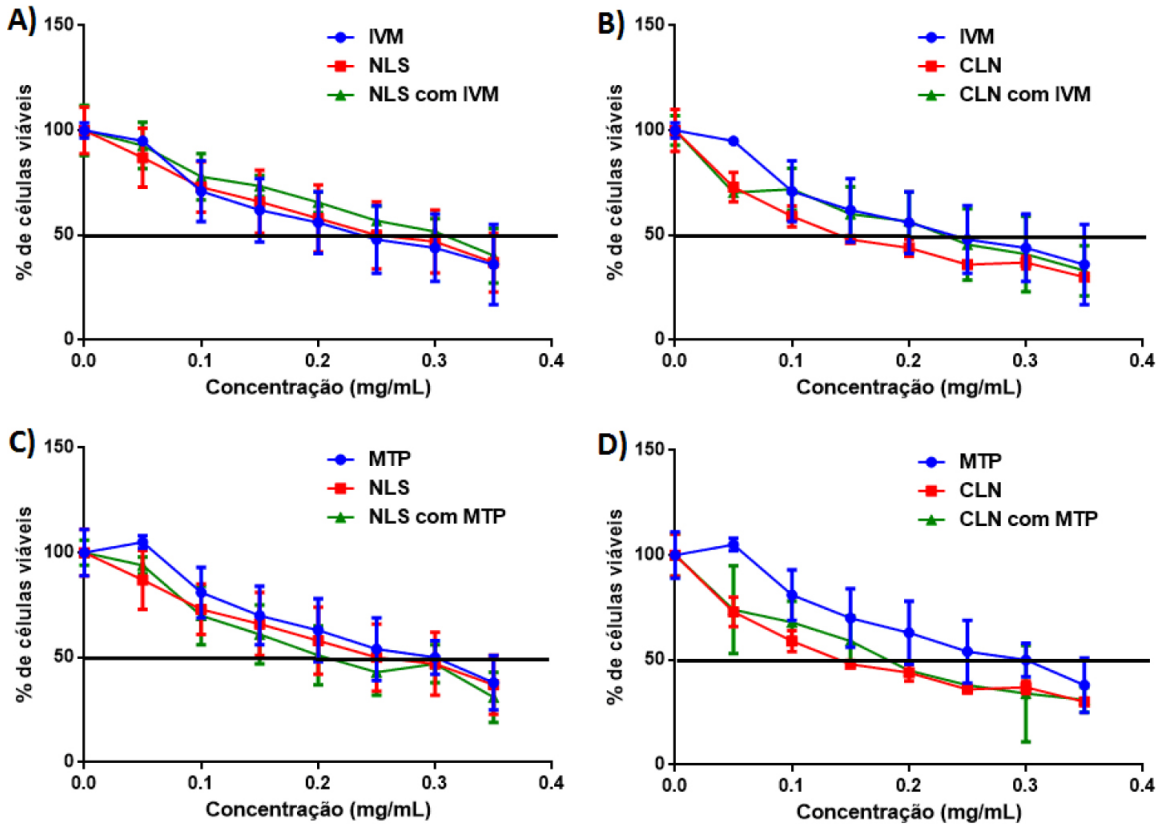

Figura 9. Avaliação da citotoxicidade de células $3 T 3$ e V79 para IVM, NLS e NLS com IVM (a); IVM, CLN e CLN com IVM (b); MTP, NLS e NLS com MTP (c); e MTP, CLN e CLN com MTP (d)

Tabela 1. Valores de $\mathrm{IC}_{50}$ para as formulações de NLS e CLN na ausência e contendo IVM e MTP, e de IVM e MTP para células 3T3 e V79

\begin{tabular}{ccc}
\hline Formulção & $\begin{array}{c}\mathbf{I C}_{\mathbf{5 0}}\left(\mathbf{m g} \mathbf{~ m L}^{-\mathbf{1}}\right) \\
\text { para 3T3 }\end{array}$ & $\begin{array}{c}\mathbf{I C}_{\mathbf{5 0}}\left(\mathbf{m g} \mathbf{~ m L}^{-\mathbf{1}}\right) \\
\text { para } \mathbf{~ V 7 9}\end{array}$ \\
\hline NLS & 0,325 & 0,261 \\
CLN & 0,100 & 0,207 \\
IVM & 0,147 & 0,251 \\
MTP & 0,146 & 0,281 \\
NLS + IVM & 0,174 & 0,295 \\
NLS + MTP & 0,181 & 0,238 \\
CLN + IVM & 0,325 & 0,234 \\
CLN + MTP & 0,115 & 0,208 \\
\hline
\end{tabular}

citotoxicidade que CLN encapsulado com os ativos IVM ou MTP, possibilitando uma melhora na viabilidade celular. Os resultados demonstram que, de forma geral, as formulações de nanopartículas com ativos encapsulados apresentam viabilidade celular acima de $50 \%$ quando testadas concentrações menores que $0,2 \mathrm{mg} \mathrm{mL}^{-1}$.

Observa-se na Tabela 1 que as células V79 apresentaram maiores valores de $\mathrm{IC}_{50}$ quando comparadas com as células 3T3, exceto para as NLS e CLN contendo IVM. Desta forma, as formulações apresentaram menor toxicidade (maior valor de $\mathrm{IC}_{50}$ ) para as células V79. Para as células V79, as formulações de NLS apresentam maiores valores de $\mathrm{IC}_{50}$ que as formulações de CLN, ou seja, apresentam menor toxicidade. O mesmo pode ser observado para as células 3T3, 
exceto quando ocorre a encapsulação de IVM, ocorrendo a inversão, ou seja, o CLN contendo IVM apresenta maior valor de $\mathrm{IC}_{50}$ que a NLS contendo IVM.

O fato das formulações de NLS apresentarem maiores valores de $\mathrm{IC}_{50}$ (menor toxicidade) quando comparadas com as formulações de CLN pode estar relacionado com a composição das nanopartículas: a alteração do núcleo lipídico provoca significativa influência no valor de $\mathrm{IC}_{50}{ }^{46}$ Desta forma, a viabilidade celular das linhagens de células testadas pode ser alterada com a alteração na composição das formulações de NLS e CLN com a redução da quantidade de lipídios e tensoativo utilizados em sua preparação, possibilitando o uso veterinário sem prejuízos aos animais tratados.

\section{Ensaio de genotoxicidade Allium cepa}

A Figura 10 apresenta os resultados para os ensaios de índice mitótico obtidos com ensaio de aberração cromossômica Allium cepa, nos quais foram avaliados os efeitos genotóxicos dos fármacos IVM e MTP, das NLS e CLN contendo os fármacos IVM e MTP, e também das NLS e CLN na ausência destes.

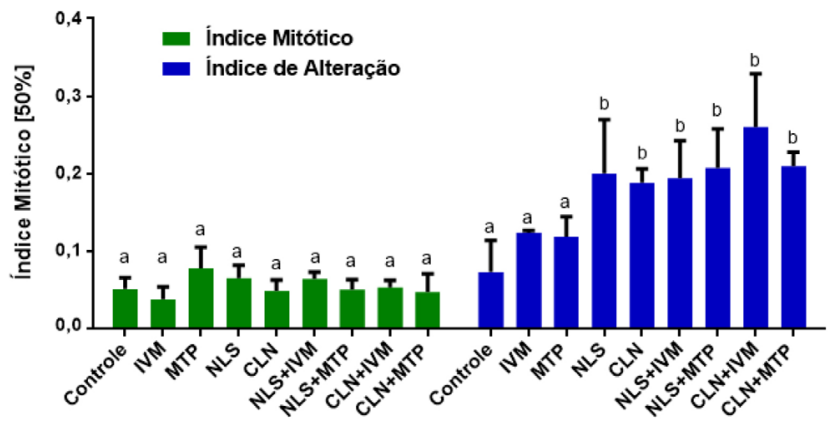

Figura 10. Avaliação da citotoxicidade e genotoxicidade de células de Allium cepa para os fármacos IVM e MTP, carreadores NLS e CLN, e formulações de NLS com IVM; CLN com IVM, NLS com MTP e CLN com MTP. Foi considerada uma significância de $p<0,05$ para as diferenças estatísticas observadas entre os grupos, onde a representa variações não significativas entre as formulações em relação ao controle; $\boldsymbol{b}$ representa variações significativas formulações em relação ao controle

Na Figura 10 estão representados os resultados dos testes de citotoxicidade dos fármacos IVM e MTP em Allium cepa, sendo que o índice mitótico representa o número de células em divisão em relação ao número total de células. Com relação à genotoxicidade pode-se observar que as formulações provocaram alterações em relação à solução controle, sendo que a NLS apresenta maior índice mitótico que CLN, tanto na presença de IVM quanto na ausência dos fármacos. Tanto as NLS como os CLN apresentaram valores de índice mitótico acima do controle, o que indica que as formulações provocam um estímulo à divisão celular. Desta forma, as formulações testadas não apresentaram citotoxicidade nas concentrações em teste.

O índice de alteração é utilizado para verificar possíveis danos ao DNA. Desta forma, pode-se observar na Figura 10 que todas as formulações testadas provocaram alterações no DNA das células testadas, sendo que o uso dos nanocarreadores NLS e CLN para encapsulação de IVM e MTP aumentaram o valor do índice de alteração destes dois ativos (IVM e MTP), aumentando as alterações no organismo testado.

\section{CONCLUSÃO}

Os resultados obtidos neste trabalho demonstram que as nanopartículas desenvolvidas (NLS e CLN) apresentam alta capacidade de encapsulação dos ativos IVM e MTP (acima de 99\%). As formulações desenvolvidas apresentaram estabilidade durante o tempo de estocagem. Por diferentes técnicas (ECF e NTA) foram obtidos valores semelhantes para a distribuição de tamanho, e também um perfil monomodal, ou seja, apenas uma população de partículas. Pode-se observar que durante o tempo de estocagem ocorreu variação na intensidade do tamanho da partícula analisada, o que pode indicar possível formação de agregados. As análises de microscopia eletrônica de transmissão mostraram que tanto as NLS como os CLN apresentam morfologia esférica, sem a presença de agregados. Os ensaios de cinética de liberação demonstraram que os perfis cinéticos dos ativos encapsulados nas NLS e CLN foram lentos. Comparando as formulações em teste, a IVM é liberada mais rapidamente que o MTP. Os resultados do ensaio de cito e genotoxicidade demonstram que as nanopartículas testadas para a encapsulação possibilitaram a alteração na viabilidade celular das células testadas. Os resultados apresentados neste trabalho demonstraram que as nanopartículas apresentaram boas características coloidais e a presença ou ausência de drogas não provocam alterações nas características das nanopartículas, possibilitando o desenvolvimento de sistemas carreadores para estes fármacos visando aplicações veterinárias.

\section{AGRADECIMENTOS}

Os autores agradecem à FAPESP pelo auxílio financeiro (processo \#2013/12322-2, \#2015/15617-9) e bolsa de mestrado para Diego Cola Faria (processo \#2013/24788-6).

\section{REFERÊNCIAS}

1. Fricker, G.; Kromp, T.; Wendel, A.; Blume, A.; Zirkel, J.; Rebmann, H.; Setzer, C.; Quinkert, R. O.; Martin, F.; Müller-Goymann, C.; Pharma Res. 2010, 27, 1469.

2. Mella, M. R.; Mendo, O. H.; Trop. Subtrop. Agroecosyst. 2010, 12, 423.

3. Gao, J.; Gu, H.; Xu, B.; Acc. Chem. Res. 2009, 42, 1097.

4. Silva, T. E. M.; Calazans, D. R. S.; Premebida, A.; Trabalho apresentado no XVI Congresso Brasileiro de Sociologia, Salvador, Brasil, 2013.

5. Pyrrho, M.; Schramm, F. R.; Cad. Saúde Pública. 2012, 28, 2023.

6. Martins, P. R.; Trabalho apresentado no $2^{\circ}$ Seminário Internacional de Nanotecnologia, Sociedade e Meio Ambiente, São Paulo, Brasil, 2005.

7. Manuja, A.; Kumar, B.; Singh, R. K.; Nanotechnol. Dev. 2012, 2, 17.

8. Booth, N. H.; McDonald, L. E.; Farmacologia e Terapêutica Veterinária, $7^{\mathrm{a}}$ ed., Guanabara Koogan: Rio de Janeiro, 1992.

9. Bill, R.; Pharmacology for veterinary technicians, $5^{\mathrm{a}}$ ed., A\&Chnicians: California, 1993.

10. McCall, J. W.; Lindemann, B. A.; Porter, C. A.; Am. J. Vet. Res. 1996 , 57, 1189.

11. Pimpão, C. T.; Rocha, R. M. V. M.; Schaefer, R.; Wouk, A. F. P. F.; Cirio, S. M.; Benato, E. M.; Gurgel, L. G. A.; Fronczak, M. A.; Revista Acadêmica: ciências agrárias e ambientais 2005, 4, 19.

12. Daglish, G. J.; Holloway, J. C.; Nayak, M. K.; J. Stored Prod. Res. 2013 , 54,8 .

13. Retnakaran, A.; Granett, J.; Ennis, T. Em Comprehensive Insect Physiology, Biochemistry, and Pharmacology; Kerkut, G., Gilbert, L., eds.; Pergamon: Oxford, 1985.

14. Dhadialla, T. S.; Carlson, G. R.; Le, D. P.; Annu. Rev. Entomol. 1998, 43,545 .

15. Henrick, C. A.; J. Am. Mosq. Control Assoc. 2007, 23, 225.

16. Müller, R. H.; Maëder, K.; Gohla, S.; Eur. J. Pharm. Biopharm. 2000, $50,161$.

17. Mehnert, W.; Mader, K.; Adv. Drug Deliv. Rev. 2001, 47, 165.

18. Wissing, S. A.; Kayser, O.; Müller, R. H.; Adv. Drug Deliv. Rev. 2004, $56,1257$. 
19. Fang, J. Y.; Fang, C. L.; Liu, C. H.; Su, Y. H.; Eur. J. Pharm. Biopharm 2008, 70, 633 .

20. Teeranachaideekul, V.; Souto, E. B.; Junyaprasert, V. P.; Müller, R. H.; Eur. J. Pharm. Biopharm. 2007, 67, 141.

21. Mandawgade, S. D.; Shobhona, S.; Pathak, S.; Patravale, V. B.; Int. J. Pharm. 2008, 362, 179.

22. Joshi, M. D.; Müller, R. H.; Eur. J. Pharm. Biopharm. 2009, 71, 161.

23. Souto, B. E.; Severino, P.; Santana, A. H. M.; Pinho, C. S.; Quim. Nova 2011, 34, 1762.

24. Vitorino, C.; Carvalho, F. A.; Almeida, A. J.; Sousa, J. J.; Pais, A. A. C. C.; Colloids Surf., B 2011, 84, 117.

25. Govender, T.; Stolnik, S.; Garnett, M. C.; Illum, L.; Davis, S. S.; J. Control. Release 1999, 57, 171.

26. Govender, T.; Riley, T.; Ehtezazi, T.; Garnett, M. C.; Stolnik, S.; Illum, L.; Davis, S.S.; Int. J. Pharm. 2000, 199, 95.

27. Venkatraman, S. S.; Jie, P.; Min, F.; Freddy, B. Y. C.; Leong-Huat, G.; Int. J. Pharm. 2005, 298, 219.

28. Schaffazick, S. R.; Guterres, S.; Freitas, L. L.; Pohlmann, A. R.; Quim. Nova 2003, 26, 726.

29. Anderson, W.; Kozak, D.; Coleman, V. A.; Jämting, Å. K.; Trau, M.; J. Colloid Interface Sci. 2013, 405, 322.

30. Jores, K.; Mehnert, W.; Drechsler, M.; Bunjes, H.; Johann, C.; Mader, K.; J. Control. Release. 2004, 95, 217.

31. Gamisans, F.; Lacoulonche, F.; Chauvet, A.; Espina, M.; Garcia, M. L.; Egea, M. A.; Int. J. Pharm. 1999, 179, 37

32. Kilic, A. C.; Capan, Y.; Vural, I.; Gursoy, R. N.; Dalkara, T.; Cuine, A.; Hincal, A.A.; J. Microencapsul. 2005, 22, 633.

33. Asrar, J.; Ding, Y.; La Monica, R. E.; Ness, L. C.; J. Agri. Food Chem. 2004, 52, 4814.
34. Paavola, A.; Yliruusi, J.; Kajimoto, Y.; Kalso, E.; Wahlström, T.; Rosenberg, P.; Pharm. Res. 1995, 12, 1997.

35. De Lima, R.; Feitosa, L.; Pereira, A. E. S.; De Moura, M. R.; Aouada, F. A.; Matosso, L. H. C.; Fraceto L. F.; J. Food Sci. 2010, 75, N89-N96.

36. De Lima, R.; Feitosa, L.; Grillo, R.; Pereira, A. E. S.; Fraceto, L. F.; J. Environ. Sci. Eng. A 2012, 1, 553.

37. Marcato, P. D.; Rev. Eletr. Farm. 2009, 6, 1.

38. Rai, S.; Paliwal, R.; Gupta, P. N.; Khatri, K.; Goyal, A. K.; Vaidya, B.; Vyas, S. P.; Curr. Nanosci. 2008, 4, 30.

39. Venuganti, V. V.; Perumal, O. P.; Em Drug Delivery Nanoparticles Formulation and Characterization; Pathak, Y., Thassu, D., eds.; New York: Informa Healthcare, 2009.

40. Mosqueira, V. C. F.; Legrand, P.; Pinto-Alphandary, H.; Puisieux, F.; Barrat, G.; J. Pharm. Sci. 2000, 89, 614.

41. Marin, E.; Briceno, M. I.; Caballero-George, C.; Int. J. Nanomed. 2013, 8,3071 .

42. http://ceqg-rcqe.ccme.ca/download/en/192, acessada em Abril 2016.

43. http://www.doc.govt.nz/Documents/science-and-technical/DSIS67.pdf, acessada em Abril 2016.

44. Chen, C. C.; Tsai, T. H.; Huang, Z. R., Fang, Y. J.; Eur. J. Pharm. Biopharm. 2010, 74, 474.

45. Müller, R. H.; Radtke, M.; Wissing, S. A.; Em Encyclopedia of Nanoscience and Nanotechonology; Nalwa, H. S., ed.; American Scientific Publishers: California, 2004.

46. Schöler, N.; Hahn, H.; Müller, R. H.; Liesenfeld, O.; Int. J. Pharm. 2002, $231,167$. 